\title{
MODERN USES AND APPLICATIONS OF RADIUM."
}

BY

\author{
HUGO LIEBER, Ph.D., \\ President, Hugo Lieber \& Company, New York.
}

When Professor Roentgen discovered the Roentgen or $\mathrm{X}$-Ray, it was generally believed that the powerful and penetrating rays emitted by the so-called Roentgen tube were produced or emitted by the bright fluorescence which constantly appeared when the Roentgen tube was in operation. This belief in the creation of these powerful rays by the fluorescence caused most of the physicists who were investigating this field to experiment with a great many fluorescent materials in order to determine whether similar powerful rays were emitted by any such materials. Among these investigators was Professor Becquerel, of Paris, who one day, after experimenting with some fluorescent uranium salts, not being able to finish his experiments that day, placed the uranium salts in a drawer of his desk. After several days, upon opening the drawer and seeing the uranium salts, he determined to continue his experiments. When he removed the uranium salts he saw that, by accident, they had been resting during this period upon a photographic plate contained in a securely-sealed envelope, such as is generally used for X-Ray and similar purposes. Becquerel then determined to develop this plate for curiosity's sake, and found to his great delight that the plate had been strongly affected by radiations of some kind. This led to further experimentation with uranium materials, leading finally to the discovery of what are now known universally as the Becquerel rays.

Madame Curie then took up the investigation of these uranium salts and soon found that pitchblende, the ore from which uranium is extracted, emitted the same radiations as the uranium salts, only in a far larger proportion. Madame Curie then obtained from the Austrian Government, which controls the

${ }^{1}$ Abstract of a paper presented at the stated meeting of the Institute, held Wednesday evening, September 20, I9I r. 
Bohemian pitchblende mines, some of the refuse of the pitchblende ore after the uranium had been extracted, and she found that this refuse was far more radioactive than either the uranium or pitchblende themselves. This convinced Madame Curie that pitchblende contained something which emitted powerful rays, apparently independent of the uranium. Further investigation led to the discovery of what Madame Curie at that time believed to be a new element, which she named Polonium, after the country from which she came. This Polonium emitted a very large quantity of radiations, which, however, were of very low penetrating power. It has since been found by Prof. Ernest Rutherford, at that time of McGill University, now of Manchester, that Polonium is not a primary radioactive element, but simply a disintegration product of the radium emanation, to which I shall refer later.

Madame Curie continued her investigations and soon found that the pitchblende refuse contained still another element which emitted the same radiations as Polonium, besides various other radiations of far greater penetrating power. This element Madame Curie named radium.

Experimentation at first led physicists, especially also Madame Curie, to believe that radium emitted three kinds of rays, which, for convenience, were called the alpha, beta, and gamma rays. The alpha rays are of very low penetrating power. They are absorbed even by tissue paper or very thin sheets of aluminum. The beta rays, which greatly resemble the Goldstein or Cathode rays, are of far greater penctrating power. Lastly, the gamma rays, which greatly resemble the Roentgen or X-Rays, are of tremendous penetrating power. I personally have been able to obtain fine photographs with these rays through twelve inches of steel.

The study of this new element was then universally taken up by physicists all over the world, and especially have the investigations of Prof. Ernest Rutherford been exceedingly fruitful. Rutherford soon found out that radium itself emits but one radiation, and that is the so-called alpha ray. But, besides this radiation, radium emits a certain gas which is called the emanation. These emanations were found to decay rapidly, and while decaying form a new product, which product also disintegrates or decomposes and in doing so forms another product, which 
likewise is subject to the same change, and so on. The various disintegration products themselves emit certain radiations, and the process of this disintegration, as determined by Rutherford, is as follows:

Radium, as stated before, emits the alpha rays, which in reality are small particles of matter that can be detected when the naked radium is exposed to a zinc sulphide screen, as the bonbardment of the screen by these particles, which travel at a remarkable velocity, produces scintillations which look like millions of shootirrg stars or sparks under a magnifying glass. Through the constant giving off of particles the radium atom gradually breaks up, but this is so slow that only one-half of the atom is broken up in about I, 300 years. Besides these alpha particles, radium emits a certain gas, which, as the writer has stated before, is called the emanation. The emanations are very unstable, one-half of them breaking up in about 3.8 days. The emanations themselves emit only alpha rays, and, as said before, rapidly decay, and while decaying form a new disintegration product, which Rutherford has named radium $A$. Radium $A$ is the most unstable of all the emanation disintegration products, one-half breaking up in about three minutes. Radium A emits only alpha rays, and when breaking up forms another product, which is called radium $B$. Radium $B$ emits no rays and is transformed in twenty-six minutes, whereby is produced radium $C$, which is the most remarkable of all the disintegration products. .ur radium $\mathrm{C}$ emits all three kinds of rays, namely, the alpha, beta, and gamma rays. Radium $\mathrm{C}$ is also transformed, and during this transformation the alpha particles which are emitted are expelled with much greater velocity than the alpha particles of the other radium products. These alpha particles are absorbed only after traversing $7 \mathrm{~cm}$. of air, while the alpha particles of the other radium products are never able to penetrate more than $4.8 \mathrm{~cm}$. of air. Besides these alpha particles, the beta and gamma rays are emitted, which are of very much greater penetrating power. Radium $\mathrm{C}$, when decomposing, forms a radioactive residue, which is called radium $D$. Radium $D$ is far more stable than the other radium products, but it does not emit any rays. Radium $D$ also decomposes and forms radium $E$, which emits only beta and gamma rays. The life of radium $\mathrm{E}$ is short, and its disintegration product is radium $F$. Radium $F$ is the final radioactive Vor. CLXXII, No. $1032-42$ 
product of radium. It is an element of high atomic weight and is identically the same product as that which Madame Curie discovered at first and named Polonium. It is also the same product which Professor Marckwald, of Berlin, discovered and named radio-tellurium. Radium $\mathrm{F}$ emits only alpha particles, but a far larger quantity of these than is emitted by any of the other radium products. Radium $\mathrm{F}$ is half transformed in $\mathrm{I} 43$ days.

If a quantity of radium emanations is left in a glass tube for some time, the glass will be covered by a radioactive deposit which can be dissolved in diluted $\mathrm{H}_{2} \mathrm{SO}_{4}$. If this solution is kept for a long time, say about a year, the activity of same will be found to have steadily increased. If polished bismuth discs are dipped into such a solution, this radium $F$ may be deposited upon them electro-chemically, and, upon removing the discs, will give off only the alpha rays but no trace of beta rays, and this very fact led Marckwald to believe that he had discovered a new element, which he called radio-tellurium.

Besides radium, there have been found other radioactive elements, especially thorium. 'Thorium is the element from which the so-called Welsbach gas mantles are made. Another radioactive element has been found which is known as emanium; it has been named emanium on account of the great quantity of emanations it emits.

As proviously stated, radium is found in pitchblende, the ore from which, in Bohemia, the uranium is extracted. Uranium is used very extensively in the manufacture of Bohemian glassware. After the uranium had been extracfed from the ore, the so-called refuse was thrown away, and only since the discovery of radium has this refuse become an extremely valuable product.

However, radium does not appear only in pitchblende, but it appears in any ore that carries uranium, as radium itself is only a product of the decomposition of uranium, and the quantity of radium which is contained in the ore is in direct proportion to the quantity of uranium contained in that ore and can be correctly measured thereby. We have pitchblende in the United States, and it is found especially in Gilpin County, Colorado. Carnotite is also found in Colorado and in some other States. Both of these minerals carry large quantities of uranium, and consequently radium. Furthermore, minor quantities of radium have been found in the so-called monazite sands of North and 
South Carolina. These are the same sands from which also the radioactive element thorium is extracted.

When radium was first introduced to the scientific world, it appeared as a grayish-yellow powder, in small, irregular crystals, and on account of its tremendously high cost was contained in small, hermetically-sealed glass tubes or vials. It must be remembered that radium itself emits only the alpha rays and emanations. The emanations and their subsequent disintegration products also give off alpha rays, and, later, beta and gamma rays. The alpha rays are of exceedingly low penetrating power and the emanations are of practically no penetrating power; but of all the radiations given off by radium and its subsequent disintegration products fully 95 per cent. consist of the alpha particles, whereas the remaining 5 per cent. consist of combined beta and gamma radiations. As radium formerly was contained only in hermetically-sealed glass tubes, all the alpha radiations, all the emanations, and even a part of the beta radiations were absorbed by the glass tube, and therefore when radium was applied in such tubes only a very small percentage of its total radiations, that is, a part of the beta rays and the gamma rays, could be utilized for physiological and other purposes. This led the writer, after due experimentation, to invent aluminum containers, that is, small containers of exceedingly thin aluminum sheets, which could be hermetically sealed by a stitable device. These containers had the advantage over the glass tubes in that they would permit all of the beta and all of the gamma rays to penetrate them; but even these extremely thin aluminum containers would absorb all the emanations and all of the alpha rays or particles. At that time it was despaired of ever being able to utilize the alpha rays and th" emanations as valuable therapeutic agents. After long experimentation, and knowing and appreciating fully the importance and necessity of obtaining radium in such a form that access could be had to the emanations as well as to the alpha radiations, and especially considering the fact that even in naked radium we are able to utilize only those alpha radiations and emanations which are emitted by the direct outside layers of a radium particle, as those emanations and alpha radiations emitted by the under layers are unable to penetrate the upper layers, and knowing that for the utilization of these alpha particles and emanations the radium to be utilized would 
have to be with practically no under layers, the writer succeeded in finally constructing what are now known as " radium coatings." Radium coatings are manufactured as follows:

Radium is dissolved in a suitable solvent. This suitable solvent must of necessity vary in accordance with the substance which is to be coated. Thus, if a metallic substance is to be coated, the solvent should contain a certain proportion of an acid which is able to affect the surface of the material to be coated. If celluloid (which the writer preferably employs) is used, the solvent should contain such ingredients which are capable of softening and affecting the surface of the celluloid, and for this purpose the writer employs largely ether, wood alcohol, acetone, amyl acetate, etc. After the radium has been thoroughly dissolved in these solvents, the proper dissolving of which requires considerable care and experience, as the slightest amount of residue would entail a comparatively large financial loss, the material to be coated, usually either rods or discs, is dipped into the solution. Or, if dipping is not advisable, that part of the material which is to be coated is covered with a small quantity of the radium solution by means of a pipette. As stated before. this radium solution contains, dissolved therein, the radium usually in the form of either radium bromide or radium chloride of varying activities. Naturally the radium solution should be spread as evenly as possible upon the surface to be coated. Then the solvent. is allowed to evaporate, which leaves the radium spread in a thin film all over the article to be coated. Since in the case of celluloid the solvent has the tendency to soften and dissolve part of the surface of the article, the deposited radium is thoroughly imbedded in the surface, whereby is fulfilled one of the principles desired, namely, to produce practically nothing but a surface of radium with as little radium as possible in underlying layers. However, if radium were used in this form for physiological purposes, it would be of very little value, for if these radium-coated rods or discs were brought in contact with any liquid or would be inserted into a diseased part and come in contact with the blood or juices of the human or animal body, the radium would completely dissolve and it would cause a complete loss of the material. It was therefore necessary to protect the radium film against loss through solution or mechanical friction, etc. This, however, was a very difficult problem, be- 
cause of the fact that the main object was to obtain full access to the alpha radiations and the emanations, for if the writer had simply coated these so-produced instruments with a protective coating the alpha radiations and the emanations would certainly have been absorbed by the coating, owing to their extremely low penetrating power. It therefore was necessary to construct a coating which would answer both purposes, namely, be thin enough so that the alpha particles and the emanations could penetrate same, and at the same time be tough and protective enough to protect the radium filament from solution in the liquids with which it might come in contact and from mechanical clestruction by friction, etc. The writer finally succeeded in doing this by gradually applying coatings of specially-prepared collodion solutions. These collodion solutions must vary in accordance with the material which has been coated with the radium, the main substance being so-called gun cotton dissolved in alcohol, amyl acetate, ether, etc., to which must be added various other ingredients. The writer finally succeeded in obtaining a coating that provided an absolute protection to the radium film and at the same time was sufficiently thin to permit the alpha radiations and the emanations to penetrate it. This penetration of the thin coating was readily proven as follows: since the alpha radiations are readily visible to the eye when they are brought in contact with zinc sulphide, whereby they produce scintillations, as is beautifully demonstrated in the Crookes spinthariscope: the same scintillation effect took place when the coated rod or disc was placed upon the surface of a zinc sulphide screen and was observed under a fairly good magnifying glass in the usual manner.

That the emanations are able to penetrate these coatings was proven in the following manner:

A rod, properly coated and protected, was placed within a glass tube, which was fairly well closed and sealed at both ends by rubber stoppers. After this coated rod was left in the glass tube for several hours (preferably twelve to twenty-four hours) a certain quantity of emanations collected within the tube. When, therefore, an air current was slowly forced through the glass tube it carried the emanations with it, and the presence of the emanations was proven by means of an electroscope.

The method of measuring radioactive materials by an electro- 
scope depends upon two well-established principles: first, that like electricity repels; secondly, that radium rays as well as radium emanations ionize the air. Ionization of the air means that the air is made a good conductor of electricity, as dry air otherwise is a non-conductor of electricity.

In the case of the Braun electroscope, an aluminum rod is suspended in a metallic case, which, for convenience, is closed off in the back and front by glass. This aluminum rod is suspended in this case by means of a piece of amber surrounded by hard rubber, both of which are non-conductors of electricity. Suspended and well balanced on this aluminum rod is an aluminum needle which moves very freely. At the lower end of the aluminum rod is an aluminum scale. When the suspended aluminum rod is charged with electricity, be it positive or negative, this electricity will instantly be conducted into the aluminum needle, and the aluminum rod and the aluminum needle will repel each other. However, only the aluminum needle can move, and will ascend the scale and will remain there until the electricity contained in the aluminum rod and the needle escapes, which escape would be extremely slow in a perfectly dry room. If we now bring radium or radium rays or emanations in the vicinity of the electroscope, these will ionize the air surrounding the electroscope and cause the electricity in the suspended rod and needle gradually to escape. The more powerful the radium is, or the larger the quantity of radiations and emanations given off, the quicker will the air be ionized, the quicker will be the discharge of electricity, and the quicker also will be the descent of the needle down the scale. By the rapidity of the descent of this needle is measured the quantity of radium or the radioactivity at our disposal.

The emanations should collect within a glass tule in which the coated rod has been contained for some time, if the writer's theory is correct that these emanations penetrate the coating. An air current blown through such a glass tube carries with it the stored-up radium emanations, and by bringing these emanations or the air charged with the emanations in contact with the electroscope the electricity contained therein always readily escapes through the ionized air and the needle of the electroscope falls more or less rapidly. 
A still more efficient means of proving that the emanations penetrate the coating is by spreading the radium solution on the inside of a tube. For such purposes the writer uses preferably celluloid tubes, internally coated with a thin radium film having the same protective coating as clescribed before. The tube is closed by means of rubber stoppers with glass stop-cocks, and all the emanations collected within this tube will follow an air current if forced through it.

In the accompanying illustration, $A$ is the celluloid tube which is coated on the inside with the radium filament and protected by the protective coating. $B$ and $F$ are the rubber

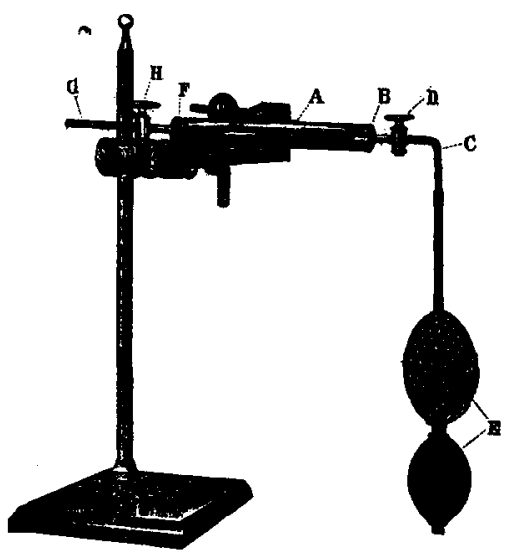

stoppers closing off the tube at both ends. Inserted in the holes of the rubber stoppers at both ends are the glass tubes $G$ and $C$ with shut-off cocks $D$ and $H$. These cocks remain closed when the tube is not in operation, so as to permit the gascous emanations to collect within the tube. Then, when it is desired to utilize the emanations, the rubber bulb $E$ is inflated, the glass cock $D$ is opened wide and the glass cock $H$ is opened very gradually. The air from $E$ is forced through $C-D$ and through the tube $A$, out through $H-G$ and carried wherever required.

If the writer's theory is correct and the emanations can penetrate the protective coating, these emanations, as stated before, collect within the tube: Then when the air is blown through the tube it carries with it the emanations. When this so-charged air is permitted to strike the top of the electroscope, the sur- 
rounding air becomes ionized and the electroscope needle descends, making it a very simple but conclusive experiment.

Thus, where formerly a glass tube containing a fairly large quantity of radium was required, which was very expensive indeed, we can obtain, by means of these coatings, the same, and even far better, results with only a small proportion of the quantity of radium formerly required. Furthermore, we have access now to all the emanations and the radiations for physiological or any other purposes desired.

The writer wants to direct attention to the following: If the beta and gamma rays, as has been asserted, are those of the greatest influence for physiological purposes or in the treatment of diseases such as cancer, lupus, etc., we must remember that these radiations are producer only by the disintegration of the radium emanation. If we now are able to take a rod or disc or any other instrument properly coated with radium and insert this into the diseased part, the emanations, whose disintegration produces these rays, will, instead of escaping into the tube and there being absorbed, now escape into the diseased part, to be retained there, to disintegrate there, and their subsequent products to produce these beta and gamma rays. Not only will these beta and gamma rays act upon the diseased part while the instrument is being applied, as was the case with the glass tube, but the radium emanation will be retained within the tissues, will continte to disintegrate, form its disintegration products, and continue to act upon these diseased parts.

An extensive series of experiments has been conducted by Prof. C. Stuart Gager, formerly of the Department of Botany. Columbia University, and now of the University of Missouri, to determine the effect of radium rays and emanations on plant life, and especially cell-formation. He has shown conclusively that in certain forms and under certain conditions radium rays, and especially the emanations emitted from a coated tube, are able to retard the growth of plants and cell-formation. Under other conditions, he very largely increased the growth as well as the cell-formation, all depending upon the various methods employed.

One important factor has to be considered in connection with these radium coatings, and that is the following: It is a wellknown fact that the waters of the famous mineral springs, 
especially those of Europe, have certain healing and beneficial qualities. It also has been established beyond a doubt that if these waters are transported their healing and beneficial qualities are almost entirely lost after a few days. It now has been demonstrated that all of these well-known waters and springs contain more or less radioactivity, that is, not primary radioactivity by having a radioactive material dissolverl therein, but what is called secondary radioactivity, such that has been intparted to these waters by having them charged with the gas or the emanations emitted by radium. After having proven this beyond a doubt, it has been the aim of a great many of our foremost investigators to artificially produce waters which would contain cmanations absorbed therein. For this purpose the celluloid tube coated on the inside with radium has been used very successfully, and it is a matter of very simple experimentation to prove the efficiency of this device and furthermore to prove the contents of radioactivity in such waters. All that is required is that the air, by means of a rubber bull), be forced through the tube which has remained closed for several hours. and the escaping air which has been chargesl with emanations allowed slowly to ooze through a column of water. which should be partaken of as quickly as possible. The writer has personally seen some very remarkable and beneficial changes produced in cases of a most desperate natire.

The celluloid tube coated on the inside also has been userl with great success in the treatment of throat and lung affections. the patient being required once or twice a day to inhale the air which slowly passes through the tube and which is charged with the emanations.

The writer also has succeeded in applying the radiunn coatings to microscopic slides. A small part of the slide is coated with the radium solution and, after evaporation of the solvent. is coated with a collodion especially prepared for this purpose. These slides have proven very efficient and of importance for biological investigations, as they can be conveniently placed under the microscope. Bacteria, cell-formation, etc., can be placed upon them, and thus the effects of the radium rays and emanations upon various microbes and cell organisms can be conveniently studied under the microscope.

In a great many cases it has been found impossible to apply 
the radium either in the form of coatings or in a tube. This occurs because of the seat of the disease and the necessity of repeated treatments. In order to provide for such cases, the writer has devised what is known as radium gelatine. This is a sterilized solution of a gelatine which contains a small quantity of radium and which will coagulate when it becomes cold. However, before becoming cold, it is charged with as large a quantity of emanations as possible. This coagulated solution is heated several times, thereby liquefying it, and each time it is again charged with emanations, so that there is finally obtained a radioactive product which contains primary as well as secondary radioactivity. This gelatine is injected into the diseased parts in liquid form or is inserted by means of tampons, etc. Experience has shown that it is readily absorbed by the surrounding diseased tissues, and the radium rays, the decaying emanations, and the disintegration products are thus brought into play upon these tissues.

Steam Engines. H. Hort. (Zeit. Ver. Deutsch Ing., lv. 943.) - This is a research on the properties of various volatile fluids which may be used, in conjunction with steam, in binary heat engines. The fluids mentioned are nitro-benzol, ammonia, sulphurous acid, and so on. The paper contains diagrams which illustrate the results obtained.

Babbitt Metal. C. H. Congdon. (The Metal Industry, ix, 9, 393.) - The rise in the price of tin has calsed a rise in the price of Babbitt metal, which contains from 80 to 90 per cent. tin, and of solder, which usually contains 40 to 50 per cent. tin. Some smelters, instead of raising the price of tin, substitute lead for more or less of the tin, ranging from 5 per cent, to 30 per cent.

Distillation of Tin in Vacuo. E. TIEDE and F. Fiscifer. (Ber., xliv, I7II.) - Tin was distilled in vacuo by placing a boat containing tin in a small electric furnace, which was placed within the distillation tube. This tube was made of glass, was kept cold by a stream of running water on the outside, and was connected with a vacuum pump. The first portion of the distillate had a brass-yellow color, due to the presence of sulphur. It was found possible to prepare tin from pure stannic chloride, which did not give this yellow sublimate unless it had been exposed for some time to the air of the laboratory. 